\section{Atividade antibacteriana em alguns extratos de vegetais do semi-árido brasileiro}

Novais,T.S ${ }^{1,5}$, Costa, J.F.O. ${ }^{1,5}$, David, J.P.L. ${ }^{2,5}$, David, J.M.., Queiroz, L.P., ${ }^{4,5}$, França, F.4,5, Giulietti, A.M. ${ }^{4,5}$, Soares, M.B.P. ${ }^{1,5}$, Santos, R.R. ${ }^{1,5 *}$

${ }^{1}$ Centro de Pesquisas Gonçalo Moniz / Fundação Oswaldo Cruz / Salvador, BA, Brasil;

${ }^{2}$ Faculdade de Farmácia;

${ }^{3}$ Instituto de Química, Universidade Federal da Bahia, Salvador/Bahia/Brasil;

${ }^{4}$ Departamento de Ciências Biológicas, Universidade Estadual de Feira de Santana, Feira de Santana, BA, Brasil; ${ }^{5}$ Instituto do Milênio do Semi-Árido.

\section{Resumo}

Espécies nativas ou endêmicas do semi-árido brasileiro foram investigadas com o intuito de se descobrir novas drogas antimicrobianas. Os ensaios foram realizados contra cepas padrões de Staphylococcus aureus e Escherichia coli através do método de difusão em disco. Dos 137 extratos de vegetais avaliados, sete apresentaram atividade significativa contra o Staphylococcus aureus. Os extratos ativos foram preparados a partir de espécies pertencentes às famílias Leguminosae e Rutaceae e serão futuramente fracionados com o intuito de se chegar às moléculas ativas.

\section{Abstract}

Species native or endemic of the Brazilian semiarid were investigated with the intention of discovering new antibacterial drugs. The rehearsals were accomplished against standard strains of Staphylococcus aureus and Escherichia coli through the diffusion method in disk. Of the 137 extracts of appraised vegetables, seven presented significant activity against the Staphylococcus aureus. The active extracts were prepared starting from species belonging to the Leguminosae and Rutaceae families and they will be fractional hereafter with the intention of arriving to the active molecules.

A origem do conhecimento do homem sobre as propriedades medicinais das plantas confunde-se com sua própria história. Há milênios os vegetais têm sido utilizados pelos seres humanos no tratamento de doenças. Porém, apenas recentemente as plantas tornaram-se objeto de estudo científico no que concerne às suas variadas propriedades medicinais, inclusive quanto à atividade antibacteriana.

Nos últimos anos, a resistência de microorganismos patogênicos a múltiplas drogas tem aumentado devido ao uso indiscriminado de antimicrobianos, comumente comercializados e usados no tratamento de doenças infecciosas. Essa situação tem forçado os cientistas à busca de novas drogas. Os vegetais são uma excelente fonte de busca de novas drogas antimicrobianas, tendo em vista que a diversidade molecular dos produtos naturais é muito superior àquela derivada dos processos de síntese química.

No semi-árido brasileiro, região que ocupa $11,5 \%$ do território nacional, estima-se haver oito mil espécies vegetais sendo que destas, 318 espécies de 42 famílias botânicas são endêmicas da caatinga ${ }^{1}$. Diante dessa vasta biodiversidade e da necessidade da descoberta de novas moléculas bioativas, é de fundamental importância o estudo farmacológico da flora dessa região, ainda pouco estudada sob esse aspecto.

Para a realização do presente estudo, espécies vegetais endêmicas ou nativas desse bioma foram randomicamente coletadas, identificadas e utilizadas para o preparo de extratos a serem testados quanto à atividade antimicrobiana.

Dentre os 137 extratos de vegetais avaliados, sete demonstraram atividade antibacteriana significativa contra Staphylococcus aureus. Nenhum dos extratos testados foi ativo contra Escherichia coli (Tabela 1). 
Tabela 1. Resultados da atividade antibacteriana dos extratos testados.

\begin{tabular}{|c|c|c|c|c|c|}
\hline Espécie & Família & $\begin{array}{l}\text { Parte do } \\
\text { Vegetal }\end{array}$ & Extrato & $\begin{array}{c}\text { Halo } \\
\text { produzido } \\
\text { contra } S . \\
\text { aureus }(\mathbf{m m})\end{array}$ & $\begin{array}{c}\text { Halo } \\
\text { produzido } \\
\text { contra } E . \\
\text { coli }(\mathbf{m m})\end{array}$ \\
\hline Esenbeckia grandiflora Mart. & Rutaceae & folhas & Acetato de Etila & 08 & 0 \\
\hline Esenbeckia grandiflora Mart. & Rutaceae & folhas & Clorofórmico & 10 & 0 \\
\hline $\begin{array}{l}\text { Galipea simplicifolia } \\
\text { (Nees \& Mart.) Engl. }\end{array}$ & Rutaceae & folhas & Clorofórmico & 16 & 0 \\
\hline Hymenaea stigonocarpa & Leguminosae & folhas & Clorofórmico & 08 & 0 \\
\hline Mart. ex Hayne & Caesalpinioideae & & & & \\
\hline Caesalpinia pyramidalis Tul. & $\begin{array}{l}\text { Leguminosae } \\
\text { Caesalpinioideae }\end{array}$ & folhas & Acetato de Etila & 10 & 0 \\
\hline Caesalpinia pyramidalis Tul. & $\begin{array}{l}\text { Leguminosae } \\
\text { Caesalpinioideae }\end{array}$ & caule & Acetato de Etila & 10 & 0 \\
\hline Acacia riparia Kunth & $\begin{array}{l}\text { Leguminosae } \\
\text { Mimosaoideae }\end{array}$ & folhas & Acetato de Etila & 11 & 0 \\
\hline
\end{tabular}

Obs.: Os halos produzidos pela droga controle (gentamicina) tiveram diâmetro de $32 \mathrm{~mm}$ para S. aureus e de $22 \mathrm{~mm}$ para E. coli.

De acordo com a literatura, a família Rutaceae é reconhecidamente biossintetizadora de metabólitos secundários biologicamente ativos, com ênfase para drogas inibidoras do crescimento de parasitas ${ }^{1,2,3,4}$ e com atividade anti-Mycobacterium tuberculosis ${ }^{5}$. No presente estudo, observou-se atividade antimicrobiana (contra S. aureus) dos extratos clorofórmico e acetato de etila das folhas da Esenbeckia grandiflora, bem como uma atividade bastante significativa do extrato clorofórmico das folhas da Galipea aff. simplicifolia, também contra o $S$. aureus. Dessa forma, os resultados obtidos confirmam uma tendência para a síntese por algumas espécies da família Rutaceae de moléculas antimicrobianas.

A família Leguminosae subfamília Caesalpinioideae possue espécies que também sintetizam moléculas bioativas. Para o gênero Caesalpinia, há uma comprovada atividade antibacteriana ${ }^{7,8}$ e antifúngica ${ }^{8}$ de algumas espécies. Pode-se, com este trabalho, comprovar a tendência para a biossíntese de metabólitos ativos por Caesalpinia pyramidalis com os resultados obtidos com o extrato acetato de etila, tanto de folhas quanto do caule da espécie. Em referência ao gênero Hymenaea, também pertencente a esta subfamília, apesar de serem escassos os relatos na literatura a respeito da atividade farmacológica de extratos ou substâncias puras sintetizadas por espécies deste gênero, comprova-se com este estudo uma atividade relevante para o extrato clorofórmico das folhas da Hymenaea stigonocarpa.

Quanto ao gênero Acacia, da família Leguminosae Mimosoideae, há relatos na literatura de atividade antibacteriana de extratos de espécies deste gênero tanto contra bactérias do trato respiratório quanto do trato gastrointestinal ${ }^{9,10}$. De acordo com os resultados encontrados com o extrato acetato de etila das folhas da espécie Acacia riparia, comprova-se a tendência para a presença de drogas antimicrobianas em extratos de espécies do gênero.

Neste estudo foram testados extratos preparados a partir de 44 espécies, das quais 5 apresentaram atividade antibacteriana. Os extratos ativos serão fracionados e purificados com o objetivo de se chegar a substâncias puras com atividade antimicrobiana. Embora a droga controle (gentamicina) tenha apresentado um significativo halo de inibição, os resultados apresentados são também considerados significativos uma vez que a gentamicina trata-se de uma substância pura e que os extratos são compostos por diversas substâncias químicas. Dessa maneira, sugere-se que as moléculas ativas encontram-se em baixa concentração, não apresentando resultados próximos ou superiores aos da droga controle utilizada.

De acordo com os resultados encontrados, pode-se com este trabalho corroborar os relatos da literatura que apontam a tendência para a biossíntese de 
metabólitos ativos das espécies das famílias Leguminosae e Rutaceae.

\section{Materiais e Métodos}

Após a coleta, os vegetais foram secos a uma temperatura de $40^{\circ} \mathrm{C}$. Exsicatas foram confeccionadas e depositadas no Herbário do Departamento de Biologia da Universidade Estadual de Feira de Santana (HUEFS). Os extratos hidroalcoólicos foram preparados a partir da maceração em MeOH: $\mathrm{H}_{2} \mathrm{O}$ (6:4) do material seco. Estes foram particionados entre $\mathrm{CHCl} 3$ e AcOEt, sucessivamente. Os extratos $\mathrm{CHCl} 3$ e AcOEt obtidos foram concentrados, secos e posteriormente submetidos aos ensaios de avaliação da atividade biológica.

Para a dissolução dos extratos secos, utilizou-se DMSO (Sigma, St. Louis, MO), ajustando-se a uma concentração final de $10 \mathrm{mg} / \mathrm{ml}$. A esterilização das amostras foi feita em irradiador emissor de radiação gama.

A técnica do antibiograma utilizada está padronizada e estabelecida na IV Edição da Farmacopéia Brasileira ${ }^{12}$. O método utilizado foi o de Kirby-Bauer, conhecido como método de difusão em disco. As bactérias utilizadas foram Staphylococcus aureus e Escherichia coli.

As placas de Petri estéreis, contendo meio Ágar MuellerHinton são impregnadas com as bactérias em suspensão em salina, com a ajuda de um swab (DME), contendo a suspensão bacteriana. Discos de papel (Sensiobio Disk) secos e estéreis, com diâmetro de $6,35 \mathrm{~mm}$ foram então depositados nas placas e posteriormente impregnados com $13 \mu \mathrm{l}$ do extrato a ser testado. A quantidade final de extrato aplicada em cada disco foi de $130 \mu \mathrm{g}$. Para o controle do experimento utilizou-se o antibiótico Gentamicina (Hipolabor) a uma quantidade final de 10 $\mu \mathrm{g} /$ disco.

As placas foram incubadas em estufa a $37^{\circ} \mathrm{C}$ durante um período de 16 a 18 horas, antes da leitura dos halos de inibição do crescimento das bactérias. Os resultados foram expressos através das medidas dos halos de inibição (em milímetros) produzidos.

\section{Bibliografia}

${ }^{1}$ Giulietti A.M., Harley R.M., de Queiroz L.P., Barbosa M.R., de Bocage Neta A.L., Figueiredo M.A. Espécies endêmicas da caatinga. In: Sampaio E.V.S.B., Giulietti A.M., Virgínio J., Gamarra-Rojas C.F.L. (eds). Vegetação e flora da caatinga. Recife: Associação Plantas do Nordeste / Centro Nordestino de Informação sobre Plantas, 2002. p.103-115.
${ }^{2}$ Carvalho L.H., Brandão M.G., Santos-Filho D., Lopes J.L., Krettli A.U. Antimalarial activity of crude extracts from Brazilian plants studied in vivo in P. bergueiinfected mice and in vitro against $P$. falciparum in culture. Braz J Med Biol Res., v.24, n.11, p.1113-1123, 1991.

${ }^{3}$ Carvalho L.H., Krettli A.U. Antimalarial chemotherapy with natural products and chemically defined molecules. Mem Inst Oswaldo Cruz, v.86, n.supl.2, p.181-4, 1991.

${ }^{4}$ Fournet A., Ferreira M.E., Rojas de Arias A., Torres de Ortiz S., Fuentes S., Nakayama H. In vivo efficacy of oral and intralesional administration of 2-substituted quinolines in experimental treatment of new world cutaneous leishmaniasis caused by L. amazonensis. Antimicrob Agents Chemother, v.40, n.11, p. 24472451, 1996.

${ }^{5}$ Jacquemond-Collet I., Benoit-Vical F., Valentin A., Stanislas E., Mallie M., Fouraste I. Antiplasmodial and citotoxic activity of galipine and other tetrahydroquinolines from Galipea officinalis. Planta Med., v.68, n.1, p. 68-9, 2002.

${ }^{6}$ Houghton P.J., Woldemariam T.Z., Watanabe Y., Yates M. Activity against Micobactyerium tuberculosis of alkaloid constituents of Angostura bark, G. officinalis. Planta Med., v.65, n.3, p.250-254, 1999.

${ }^{7}$ Saeed M.A., Sabir A.W. Antibacterial activity of Caesalpinia bonducella seeds. Fitoterapia, v.72, n.7, p.807-809, 2002.

${ }^{8}$ Woldemichael G.M., Singh M.P., Maiese W.M., Timmermann B.N. Constituents of antibacterial extracts of Caesalpinia paraguaiensis Burk. ZNaturforsch., v.58, n.1-2, p.70-75, 2003.

${ }^{9}$ Simin K., Khaliq-Uz-Zaman S.M., Ahmad V.U. Antimicrobial activity of seeds extracts and bondenolide from Caesalpinia bonduc (L.) Roxb. Phytother Res., v.15, n.5, p. 437-440. 2002.

${ }^{10}$ Palombo E.A., Semple S.J. Antibacterial activity of Australian plant extracts against methicilin-resistant Staphylococcus aureus (MRSA) and vancomycinresistant enterococci (VRE). J Basic Microbiol., v.46, n.6, p. 2002: 46 (6): 444-448, 2002.

${ }^{11}$ Clark D.T., Gazi M.I., Cox S.W., Eley B.M., Tinsley G.F. The effects of Acacia arabica gum on the in vitro growth and protease activities of periodontopathic bacteria. J Clin Periodontol., v.20, n.4, p. 238-243, 1993.

${ }^{12}$ Farmacopéia Brasileira. 4.ed. São Paulo: Atheneu, 1988. 
* Autor para correspondência:

Ricardo Ribeiro dos Santos

Centro de Pesquisas Gonçalo Moniz

Fundação Oswaldo Cruz.

Rua Waldemar Falcão, 121 - Brotas

Salvador - BA - Brasil

CEP: 40295-001

Tel: (71) 356-4320 Ramal 260

Fax: (71) 356-4320 Ramal 292

E-mail:rrsantos@cpqgm.fiocruz.br
Atividade antioxidante de substâncias presentes em Dioclea violacea e Erythroxylum nummularia

Barreiros, A.L.B.S ${ }^{1}$; Barreiros, M.L.' ; David, J.M. ; David, J.P.2;

Queiroz, L.P. $\mathrm{de}^{3}$

1'Instituto de Química;

${ }^{2}$ Faculdade de Farmácia, Universidade Federal da Bahia, 40170-280, Salvador, BA, Brasil;

${ }^{3}$ Departamento de Ciências Biológicas - Universidade Estadual de Feira de Santana, 44031-460, Feira de Santana, BA, Brasil

\begin{abstract}
This work describes the evaluation of the antioxidant activity in the system b-carotene/linoleic acid and radical scavenging effects of the substances 2 ', 4 'dihydroxychalcone, 2',3,4,4'-tetrahydroxychalcone (butein), 4-methoxy-2',3,4'-trihydroxychalcone, 7hydroxyflavanone, 3',4',7-trihydroxyflavanone (butin), 7,4'-dihydroxyflavanone (liquiritigenin), 6-methoxy-7hydroxydihydroflavonol and lasiodiplodin isolated of the extract $\mathrm{CHCl} 3$ of the stem of Dioclea violacea and 3',4',5,7-tetrahydroxyflavanol (quercetin), 4',7dimethoxy-3',5-dihydroxyflavanol and epicatechin isolated of the Erythroxylum nummularia leaves. These compounds were evaluated and compared with the antioxidant standards n-propyl gallate, BHT and $\alpha$ tocoferol.
\end{abstract}

As substâncias antioxidantes estão envolvidas na prevenção do desenvolvimento de várias patologias relacionadas ao stress oxidativo, dentre elas o câncer, doenças cardiovasculares, além de seu papel em retardar o envelhecimento das células ${ }^{1}$. Os flavonóides em geral se destacam por sua atividade antioxidante, e é conhecida a relação desta atividade em função da estrutura ${ }^{2,3}$.

O estado da Bahia registra a ocorrência de várias espécies das famílias Leguminosae e Erythroxilaceae, sendo muitas delas endêmicas. Ate o presente momento apenas duas espécies do gênero Dioclea foram estudadas sob o ponto de vista químico e farmacológico: as raízes de D. grandiflora4, e o caule de $D$.

Rev. Bras. Farmacogn., v. 13 supl 2, p. 08-11, 2003. 